\title{
GMR
}

\section{Relationship between estrogen receptor 1 gene polymorphisms and postmenopausal osteoporosis of the spine in Chinese women}

\author{
D.P. Shang, H.Y. Lian, D.P. Fu, J. Wu, S.S. Hou and J.M. Lu \\ Zhongshan Hospital Affiliated of Dalian University, Dalian, Liaoning, China \\ Corresponding author: J.M. Lu \\ E-mail: lujianmin_1@163.com \\ Genet. Mol. Res. 15 (2): gmr. 15028106 \\ Received November 19, 2015 \\ Accepted January 18, 2016 \\ Published June 3, 2016 \\ DOI http://dx.doi.org/10.4238/gmr.15028106
}

\begin{abstract}
The purpose of this study was to evaluate single nucleotide polymorphism (SNP) variants of the estrogen receptor 1 gene (ESR1) at rs2234693 and rs9340799, as well as to investigate the relationship between ESR gene polymorphisms and postmenopausal osteoporosis (OP) of the spine in Chinese women. We recruited 198 postmenopausal women with OP and 276 healthy women between May 2012 and September 2015 in Zhongshan Hospital. Dual energy x-ray absorptiometry was used to measure the bone mineral density (BMD) of the lumbar vertebrae in all subjects. In addition, PCR-restriction fragment length polymorphism based analysis was conducted to identify the genotypes of ESR1. The distribution of ESR1 in the osteoporosis group and the control group was determined; the relationship between ESR polymorphisms and BMD was analyzed. The distributions of BMD were: $\mathrm{TT}<\mathrm{TC}<\mathrm{CC}, \mathrm{GG}<\mathrm{AG}<\mathrm{AA}$. The TT, TTGG, and TCGG genotypes were found to be lower as compared to the other genotypes. Stratified analysis suggested that the TT genotype and the combined genotypes TTGG and TCGG were significantly higher in the OP group as compared to the control group $(\mathrm{P}<0.01)$. Therefore, ESR1
\end{abstract}


polymorphisms at rs2234693 and rs9340799 may be associated with OP, and could be used as markers to screen those with high risks to postmenopausal OP in Chinese women.

Key words: Osteoporosis postmenopausal; Bone mineral density; Estrogen receptor 1 polymorphisms; Spine

\section{INTRODUCTION}

Osteoporosis (OP) is a disease of the bone tissue microstructure, where bone mass is reduced due to increased bone loss. As a result, the bones can become brittle and are easily fractured (Liu et al., 2011). According to recent statistics, there are 2 billion people with OP, and in the United States alone, there are approximately 2400 million people with osteoporosis. In addition, there are 1000 million OP patients and 150 million osteoporotic fractures (OPF) every year. The direct medical costs for patient care amounts to approximately 140 billion dollars, which is also steadily increasing (Yang and Zhou, 2008; Zhao and Sun, 2010). Based on present estimates, by the middle of next century, there would be over 2.1 billion OP patients, which would place huge medical and economic burdens on the country. At present, the incidence of OP is continuously increasing, and OP-related fractures have serous effects on the quality of life for many people. Gene polymorphisms may play an important role in the pathogenesis of this disease (Bustamante et al., 2007), and may be used as a diagnostic tool for early detection and prevention of $\mathrm{OP}(\mathrm{Wu}, 2011)$.

The ESR1 gene, which encodes the estrogen receptor (ER)- $\alpha$, has 4 polymorphisms. The ESR2 gene, which encodes ER $\beta$, has 3 polymorphisms. Owing to the availability of genetic data for these 7 polymorphisms in the 2 ER genes, we have the opportunity to examine their associations with bone mineral density (BMD) (Greendale et al., 2006).

$E R \alpha$ and ER $\beta$ are each expressed in osteoblasts and osteoclasts (Lim et al., 1999; Bland, 2000; Bord et al., 2001). The potential roles of the 2 ER isoforms in bone homeostasis are under intense investigation. To date, studies on the relationship between BMD and ERs in humans (predominantly women) have mainly focused on 2 intronic polymorphisms in the ESR1 gene. These 2 polymorphisms are commonly labeled as PvuII and $\mathrm{XbaI}$ in reference to the restriction endonucleases used to characterize the polymorphisms. To a much lesser extent, the association between BMD and a polymorphism in the promoter region of ESR1 characterized by variable numbers of TA repeats, has also been studied (Ioannidis et al., 2002; Gennari et al., 2005). Of these frequently studied polymorphisms, 2 were included in the genetics data analyzed by the Sex Steroid Hormone Genetics Protocol of the SWAN Genetics Study: PvuII and XbaI, also referred to by their rs numbers, ESR1 rs2234693 and ESR1 rs9340799, respectively.

The evidence linking ESR1 rs2234693 and ESR1 rs9340799 to BMD is mixed; some studies have shown no association, whereas others have shown an association with BMD (Gennari et al., 2005). Furthermore, genotypes associated with higher or lower BMD vary among studies, and the associations between polymorphisms in ESR1 and bone density are inconsistent across racial or ethnic groups (Greendale et al., 2006).

The purpose of this investigation was to evaluate single nucleotide polymorphism (SNP) variants of the estrogen receptor 1 (ESR1) at rs2234693 and rs9340799, and to determine the relationship between ER gene polymorphisms and postmenopausal osteoporosis of the spine in Chinese women. 


\section{MATERIAL AND METHODS}

\section{Subjects}

We recruited 198 postmenopausal women with osteoporosis as well as 276 healthy women between May 2012 and September 2015 in Zhongshan Hospital. DEXA was used to measure the BMD of the lumbar vertebrae (LS-BMD) in all subjects, and PCR-RFLP was conducted to identify the genotypes of ER1. The exclusion standards included early ( $<45$ years old) and late menopause ( $>54$ years old), complicated OP; other low BMD diseases such as osteomalacia, hyperthyroidism, metastatic bone cancer, multiple myeloma, vertebral hemangioma, and pyogenic spondylitis. No subjects were related to each other. All participants gave informed written consents, and the study was approved by the ethics committee at the institution.

\section{Genotyping}

Blood samples were obtained from all subjects in the morning, after an overnight fast. Venous blood $(5 \mathrm{~mL})$ was drawn into vacutainer tubes containing the anticoagulant EDTA. Blood samples were centrifuged at $3000 \mathrm{rpm}$ for 10 minutes. The buffy coat and red blood cell pellet were used for DNA extraction using the total blood DNA extraction kit (QIAGEN Biotechnology Company). Genomic DNA was amplified by polymerase chain reaction (PCR) using ER1 (rs2234693 and rs9340799) specific primers (Table 1). PCR condition was as follows: initial denaturation at $94^{\circ} \mathrm{C}$ for $3 \mathrm{~min} ; 30$ cycles at $94^{\circ} \mathrm{C}$ for $1 \mathrm{~min}, 55^{\circ} \mathrm{C}$ for $1 \mathrm{~min}$, $72^{\circ} \mathrm{C}$ for $5 \mathrm{~min}$; final extension at $72^{\circ} \mathrm{C}$ for $7 \mathrm{~min}$. Restriction enzyme digestions were used to determine the ER1 rs2234693 and rs9340799 variants, respectively (Table 1). The resulting fragments were analyzed on $2 \%$ agarose gels.

Table 1. Primer sequences and methods used for detection of ER1 gene polymorphisms.

\begin{tabular}{l|l|l}
\hline & Primer sequence & Method \\
\hline rs2234693 & $\begin{array}{l}\text { Forward: 5'-CTGCCATCTTTTCCTATTCTCC-3'; } \\
\text { Reverse: 5'-TCTTTCTCTGCCACCCTGGCGTCGATTATTATCTGA-3' }\end{array}$ & PvuII based RFLP \\
\hline rs9340799 & $\begin{array}{l}\text { Forward: 5'-CTGCCATCTTTTCCTATTCTCC-3'; } \\
\text { Reverse: 5'-TCTTTCTCTGCCACCCTGGCGTCGATTATTATCTGA-3' }\end{array}$ & XbaI based RFLP \\
\hline
\end{tabular}

RFLP: restriction fragment length polymorphism.

\section{Bone measurements}

BMD in the lumbar spine (LS-BMD) was measured in grams per square centimeter with the Hologic densitometers (Hologic Inc., Waltham, MA). Bone density scans used in the current analysis were obtained at cohort baseline, when all women were designated as premenopausal or in early perimenopause on the basis of self-reported menstrual bleeding pattern variations. We considered the cohort baseline BMD values to be approximate to peak bone mass.

\section{Statistical analysis}

All SNP data were evaluated for Hardy-Weinberg equilibrium. Data were analyzed using the chi-square test and the Fisher's exact test where appropriate. Analysis of variance 
(ANOVA) was used to quantify the associations between LS-BMD and each of the ESR1 genotypes. All significant tests were 2-sided. Statistical analysis was performed using the SPSS version 20.0 software. For results where $\mathrm{P}<0.05$, the exact $\mathrm{P}$ values were given.

\section{RESULTS}

\section{ESR1 polymorphisms}

As shown in Table 2, in ER1 rs2234693, the frequency of the TT genotype was the highest in OP group, and the CC genotype was the highest in control group. In addition, there were significant differences in the TT and $\mathrm{CC}$ genotypes between the 2 groups $(\mathrm{P}<0.01)$. In ER1 rs9340799, there were 6 (3.2\%), 46 (23.1\%), and 146 (73.7\%) OP individuals with the AA, AG, and GG genotypes, respectively. In the control group, the AA, AG, and GG genotypes were $10(3.5 \%), 84(32.4 \%)$, and 182 cases (64.1\%), respectively. Even though the GG genotype was common in the OP group, there was no difference between two groups (P $=0.279$ ). Results of the genotype frequencies are shown in Table 3. The distribution of the TTGG genotype differed significantly between OP group and the controls $(P=0.000)$. The TCGG genotype was significant higher in the OP group as compared to the healthy individuals, as demonstrated in Table 4.

Table 2. Genotype frequencies of ER1 rs2234693.

\begin{tabular}{l|c|c|c|c}
\hline \multirow{2}{*}{ Group } & \multirow{2}{*}{$\mathrm{N}$} & \multicolumn{3}{|c}{ Genotype frequency (\%) } \\
\cline { 3 - 5 } & & $\mathrm{TT}$ & $\mathrm{TC}$ & CC \\
\hline OP group & 198 & 35.2 & 50.7 & 14.1 \\
\hline Control group & 276 & 10.2 & 39.9 & 49.9 \\
\hline$\chi 2$ & & 17.654 & 1.825 & 22601 \\
\hline $\mathrm{P}$ & & 0.000 & 0.183 & 0.000 \\
\hline
\end{tabular}

Table 3. Genotype frequencies of ER1 rs9340799.

\begin{tabular}{l|c|c|c|c}
\hline \multirow{2}{*}{ Group } & \multirow{2}{*}{$\mathrm{N}$} & \multicolumn{3}{|c}{ Genotype frequency (\%) } \\
\cline { 3 - 5 } & & AA & AG & GG \\
\hline OP group & 198 & 3.2 & 23.1 & 73.7 \\
\hline Control group & 276 & 3.5 & 32.4 & 64.1 \\
\hline$\chi 2$ & & 0.031 & 2102 & 2087 \\
\hline P & & 0.903 & 0.167 & 0.279 \\
\hline
\end{tabular}

Table 4. Combined genotype frequencies of ER1 in two groups.

\begin{tabular}{|c|c|c|c|c|c|c|c|c|}
\hline \multirow[t]{2}{*}{ Group } & \multirow[t]{2}{*}{$\mathrm{N}$} & \multicolumn{7}{|c|}{ Combined genotype frequency $(\%)$} \\
\hline & & CCGG & TCGG & TCAG & TCAA & TTGG & TTAG & TTAA \\
\hline OP & 198 & 14.9 & 39.2 & 10.3 & - & 19.3 & 12.5 & 3.8 \\
\hline Control & 276 & 51.1 & 12.2 & 25.1 & 2.4 & 0.8 & 7.9 & 0.5 \\
\hline Total & 474 & 36.1 & 23.6 & 18.8 & 1.5 & 8.4 & 9.7 & 1.9 \\
\hline
\end{tabular}

\section{Relationship between LS-BMD and ESR1 polymorphisms}

The LS-BMD Z value of the TT genotype was the lowest, which showed the trend: $\mathrm{TT}<\mathrm{TC}<\mathrm{CC}$; the differences between the groups were statistically significant $(\mathrm{P}=0.000)$ 
in ER1 rs2234693. Additionally, the LS-BMD Z value showed the trend: $\mathrm{GG}<\mathrm{AG}<\mathrm{AA}$ in ER1 rs9340799, and the differences between the groups were also statistically significant ( $P$ $=0.000$ ). Results are shown in Table 5. Lastly, the BMD Z value of the TTGG genotype was the lowest (Table 6).

Table 5. Relationship between ER1 genotypes with BMD Z values.

\begin{tabular}{l|c|c|c}
\hline Gene & TT & TC & CC \\
\hline BMD Z value & $-2.79 \pm 1.46$ & $-1.67 \pm 0.91$ & $-1.54 \pm 0.35$ \\
\hline Gene & AA & AG & GG \\
\hline BMD Z value & $-0.35 \pm 2.19$ & $-1.65 \pm 0.02$ & $-1.98 \pm 0.91$ \\
\hline
\end{tabular}

Table 6. Relationship between ER1 combined genotype with BMD Z values.

\begin{tabular}{l|c|c|c|c|c|c|c}
\hline Gene & TTAA & TCAA & TTAG & TCAG & TTGG & TCGG & CCGG \\
\hline BMD Z value & $-0.67 \pm 3.29$ & $-2.29 \pm 0.78$ & $-3.28 \pm 1.12$ & $0.00 \pm 0.56$ & $-1.07 \pm 0.51$ & $-2.23 \pm 0.88$ & $-1.53 \pm 0.35$ \\
\hline
\end{tabular}

\section{DISCUSSION}

BMD is used to diagnose OP, and is used to evaluate OP fracture. It has been found to be influenced by both environmental and genetic factors. At the present, it has been hypothesized that various candidate genes polymorphisms such as vitamin D, ER gene, IL-6, and TGF may be associated with variations in BMD (He et al., 2004; Li et al., 2005; Lei et al., 2005; Ye et al., 2006).

Estrogens are bone trophic agents. Cohort studies reported a strong, positive association between BMD and serum estradiol and estrone levels in adults of both sexes (Greendale et al., 1997; Khosla et al., 2001). As estrogen receptors mediate estrogens' effects, it is rational to hypothesize that variations in ER genes could result in variation in BMD (Gennari et al., 2005)

Interestingly, studies examining the specific associations between BMD and ESR1 or ESR2 polymorphisms found varied results in different races/ ethnicities (Greendale et al., 2006). In this study, we found that the distribution of ER gene polymorphisms differed between races and regions. The distribution frequencies in Chinese women were consistent with that of postmenopausal women in Japan, and their relationship with BMD was as follows: $\mathrm{TT}<\mathrm{TC}<\mathrm{CC}, \mathrm{GG}<\mathrm{AG}<\mathrm{AA}$. On the other hand, in western countries such as Finland, a different trend was found: TT $>$ TC $>$ CC, GG $>$ AG $>$ AA (Carling et al., 1997; Ushiyama T et al., 1998). These differences in gene polymorphisms may explain the variations in BMD. Two group analyses revealed that the distribution frequency of the TT genotype was higher in the OP group as compared to the control group $(\mathrm{P}<0.01)$. The distributions of the combined genotypes TTGG and TCGG were also found to be significantly higher in the OP patients as compared to the control group $(\mathrm{P}<0.01)$. Therefore, it is possible that these 3 genotypes are associated with susceptibility to spine osteoporosis.

In summary, this study found that estrogen receptor 1 gene polymorphisms may be associated with postmenopausal osteoporosis of the spine in Chinese women. Therefore, ER gene could be employed as a selection method to identify individuals with higher risk to OP, which may decrease the risk of OP fracture and implement early prevention techniques. Furthermore, ER gene polymorphism may be used to select potential treatments and test drug efficacy in OP patients. 


\section{Conflicts of interest}

The authors declare no conflict of interest.

\section{REFERENCE}

Bland R (2000). Steroid hormone receptor expression and action in bone. Clin. Sci. 98: 217-240.http://dx.doi.org/10.1042/ cs0980217

Bord S, Horner A, Beavan S and Compston J (2001). Estrogen receptors alpha and beta are differentially expressed in developing human bone. J. Clin. Endocrinol. Metab. 86: 2309-2314.

Bustamante M, Nogués X, Enjuanes A, Elosua R, et al. (2007). COL1A1, ESR1, VDR and TGFB1 polymorphisms and haplotypes in relation to BMD in Spanish postmenopausal women. Osteoporos. Int. 18: 235-243. http://dx.doi. org/10.1007/s00198-006-0225-8

Carling T, Rastad J, Kindmark A, Lundgren E, et al. (1997). Estrogen receptor gene polymorphism in postmenopausal primary hyperparathyroidism. Surgery 122: 1101-1106. http://dx.doi.org/10.1016/S0039-6060(97)90214-2

Gennari L, Merlotti D, De Paola V, Calabrò A, et al. (2005). Estrogen receptor gene polymorphisms and the genetics of osteoporosis: a HuGE review. Am. J. Epidemiol. 161: 307-320. http://dx.doi.org/10.1093/aje/kwi055

Greendale GA, Edelstein S and Barrett-Connor E (1997). Endogenous sex steroids and bone mineral density in older women and men: the Rancho Bernardo Study. J. Bone Miner. Res. 12: 1833-1843. http://dx.doi.org/10.1359/ jbmr.1997.12.11.1833

Greendale GA, Chu J, Ferrell R, Randolph JF, Jr., et al. (2006). The association of bone mineral density with estrogen receptor gene polymorphisms. Am. J. Med. 119 (Suppl 1): S79-S86.http://dx.doi.org/10.1016/j.amjmed.2006.07.011

He JW, Huang QR, Zhang ZL, Qin YJ, et al. (2004). Association of polymorphisms of estrogen receptor-a and vitamin D receptor genes with peak bone mass in Shanghai women. Chin. J. Endocrinol. Metab 2: 140-142.

Ioannidis JP, Stavrou I, Trikalinos TA, Zois C, et al.; ER-alpha Genetics Meta-Analysis (2002). Association of polymorphisms of the estrogen receptor alpha gene with bone mineral density and fracture risk in women: a metaanalysis. J. Bone Miner. Res. 17: 2048-2060. http://dx.doi.org/10.1359/jbmr.2002.17.11.2048

Khosla S, Melton LJ, 3rd, Atkinson EJ and O'Fallon WM (2001). Relationship of serum sex steroid levels to longitudinal changes in bone density in young versus elderly men. J. Clin. Endocrinol. Metab. 86: 3555-3561. http://dx.doi. org $/ 10.1210 /$ jcem.86.8.7736

Lei SF, Wu Y and Deng HW (2005). Study progress of association of the vitamin D receptor a gene with OP. Chin. J. Geriatrics 24: 473-475.

Li HL, Gong XH and Huang YK (2005). Association of the vitamin D receptor gene start codon polymorphism with vitamin D deficiency rickets. Chin. J. Pediatr. 22: 105-107.

Lim SK, Won YJ, Lee HC, Huh KB, et al. (1999). A PCR analysis of ERalpha and ERbeta mRNA abundance in rats and the effect of ovariectomy. J. Bone Miner. Res. 14: 1189-1196. http://dx.doi.org/10.1359/jbmr.1999.14.7.1189

Liu CL, Wu Y and Bi LF (2011). Progress in osteoporosis-related gene research. Chin J. Osteoporos. 8: 731-735.

Ushiyama T, Ueyama H, Inoue K, Nishioka J, et al. (1998). Estrogen receptor gene polymorphism and generalized osteoarthritis. J. Rheumatol. 25: 134-137.

Wu D (2011). The application of molecular genetics in osteoporosis diagnosis. Chin. J. Osteoporos. 17: 440-452.

Yang WH and Zhou JL (2008). Commentary on effects of calcium and vitamin d supplementation on prevention of osteoporotic fractures. Chin. J. Osteoporos 14: 797.

Ye W, Peng Y and Huang DS (2006). Association of the promoter -509 C > T polymorphism of transforming growth factor$\beta 1$ with lumbar disc disease. Orthopedic J. China 14: 531-534.

Zhao YC and Sun CT (2010). Diagnosis of osteoporotic vertebral compression fracture. Chin. J. Spine Spinal Cord 20: 250-251. 